\title{
Radical Design for Sustainability: 'Personal Meaning' as the Fourth Bottom Line in Stuart Walker
}

\author{
Pantaleão, Lucas Farinelli ${ }^{1, a}$, Pinheiro, Olympio José ${ }^{2}$ \\ ${ }^{1}$ Federal University of Uberlândia, FAUeD, Brazil \\ ${ }^{2}$ São Paulo State University, FAAC, Brazil
}

\begin{abstract}
This paper introduces Stuart Walker's conceptualisation of personal meaning as a fourth bottom line of design for sustainability. As a sustainable radical approach of design, the additional pillar seeks to extend the triple bottom line towards a "post-materialistic" (Mathews) conciliatory unity of historical human needs, levels of meaning and cultural worldviews. Philosophical and spiritual concepts based on millennial religious traditions (Eastern and Western) are rescued to the sphere of functional design objects as an alternative to re-signify the prevalent naturalist-materialist ideology. From this reference, we seek to contribute to the reflections of design, whose approach also integrates a radical dimension of sustainability in order to transcend the current challenges of the economic, social and environmental crises of contemporary post-industrial society.
\end{abstract}

Keywords. Sustainable Radical Design; Quadruple Bottom Line; Personal Meaning; Spiritually Useful Design; Form Follows Meaning; Stuart Walker.

\section{Introduction: Toward the spiritual ${ }^{1}$ in design}

"The lack of any spiritual basis for design will make ethical and environmental considerations mere well-intentioned afterthoughts." (PAPANEK, 1995; 235)

"It is possible to imbue functional objects with symbolic references that more directly link day to day activities with deeper notions of meaning. [...] In doing so, we will be discovering the true spirit of design." (WALKER, 2011; 210)

As Papanek already discussed in the 1970s, "as designers have begun to function as a long-range planner on upper managerial levels, members of profession have lost integrity and responsibility" (PAPANEK, 1997; 159). A sad example of this fact is that the very term 'sustainable product design' encouraged the manufacture of more and more products to replace products not considered 'sustainable'.

Subsequent to the closing of the Ulm School (Hochschule für Gestaltung-HfG) in 1968, Victor Papanek became established as a pioneering and visionary advocate of ecological ideals and socially responsible design. His work Design for the Real World

\footnotetext{
${ }^{1}$ We follow Victor Papanek's example in the third chapter of his book "The Green Imperative" (1995) and have employed the term "spiritual" as sinonomous of "essential". Regarding any possible association to some kind of supernatural entity (common sense), the "spiritual dimension"-as a simple conceptual abstraction-is intended to summarise here a complementary opposition of the material (physic) dimension.
}

(1971), when proposing a new attitude to the consumer industry, forcefully protested for the ethics and responsibility of designers and manufacturers towards planetary sustainability.

In this context, once design is associated with publicity, Papanek accused it of having the possibility to become one of the most dangerous practices on the planet and in society because it is dedicated to convincing people to buy what they do not need, with the money they do not have, in order to impress others who do not care (PAPANEK, 1977; 12). For him, this was probably the worst aspect of design in society at that time.

This point of view seems to resonate with some of Stuart Walker's arguments, whose work comprises the fundamental theoretical reference of our paper.

Walker is currently a Professor of Design for Sustainability and co-director of the Imagination Lancaster design research centre at Lancaster University, UK. He is the principal editor of the Handbook of Design for Sustainability (2013). Walker employs the creative design process itself as an approach of inquiry, which honours both the core practice and creative potential of designing sustainability (WALKER, 2014). His research focuses on the aesthetics of sustainable functional products and his work focuses on the sustainable aesthetics of design and its re-signification. Through the rescue of Eastern and Western spiritual understanding of millennial religious traditions, Walker develops a propositional (academic) design that has been exhibited across Canada, Italy and the UK, including an 
exhibition at the Design Museum in London and John Ruskin's home (Brantwood) at Coniston in the English Lake District.

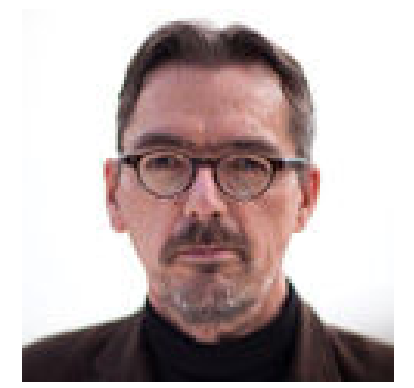

Figure 1. Stuart Walker

Both Papanek and Walker seem to believe that an authentic relation of a design project to sustainability lives in what they define as the "spiritual values of design” (PAPANEK, 1995: 49-74; WALKER, 2011: 111-24). When designing, these immaterial values start from the "designer's intent" (PAPANEK, 1995: 53-8; WALKER, 2011: 190-2) to, in turn, imprint the "intrinsic properties" (WALKER, 2006: 187-9; 2014: 92-4) on the project.

For the authors, the design spirit would be found in the harmonic adequacy between notions of meaning and purpose of the project. To adjust to its real and true function-the use, per se, by the user himself-this homeostatic equilibrium expresses, naturally, the form of the product/object/artefact. Designed by an immaterial principle - the moral awareness - the harmonic balance of these factors would be able to provide the true sustainable design, in which theory, practice, ethics and aesthetics are fully compliant.

In the words of Papanek (1995): "There is a point at which beauty and high utility through good design interconnect. If both conditions exist simultaneously in an object, and are furthermore clear expressions of the social intent of the people who designed it, it is possible to speak of the spiritual in design. [...] We are still looking for a new reality-based aesthetic direction. Concern for the environment and for the disadvantaged of our society are the most profound and powerful forces with which to shape design [...] Lifestyle changes will be required to make many of the most radical changes acceptable. [...] I firmly believe that it is the intent of the designer as well as the intended use of the designed object that can yield spiritual value. [...] As we practice our art and skill, what we do moulds who we are and what we are becoming" (Ibid: 57-8; 53).

In this same sense, Walker points out that, according his design approach: "designing sustainability demands an approach in which ethical and spiritual considerations, environmental responsibilities and practical requirements become synthesised via the process of designing, and manifested through aesthetic expressions that speak of a deeper kind of beauty, one that transcends mere surface and style" (WALKER, 2014: 46).

Since environmental concerns have emerged within the scope of design activity, it is worth questioning the extent to which design can contribute to human development synchronisation to the new systemic, holistic and ecological paradigms in the context of the post-industrial society? In design, is it possible to use personal meanings for purposes aimed at raising awareness of an ecologically sustainable society? Would it really be legitimate to think about a design spirit that is ethically sensible and aesthetically sustainable?

From the inclusion of factors such as human experience, (self) awareness development and inner values, this article aims to promote an updated reflection regarding one of the approaches of so-called sustainable radical design (WALKER, 2008; PANTALEÃO and PINHEIRO, 2016a). In this direction, Walker's quadruple bottom line (QBL) conceptualisation proposes the inclusion of personal (inner) meaning as a fourth tool that is capable of improving the pedagogy of design for sustainability (WALKER, 2011: 127-9; 2014: 11-14).

Regarding the responsibility that both design theory and methodology share - today more than ever-of complex ecosystemic impositions to ensure a more sustainable future, this paper seeks to contribute to design reflection, including setting out different approaches in a more radical (spiritual) dimension.

\section{Stuart Walker's Quadruple Bottom Line for Sustainable Design}

"Religiousity is not necessarily spirituality. They overlap. But one is exclusive, text-based only and generally closed to other systems and worldviews. The spiritual is not linked to race or nation. However, it is certainly the deeper part of every religion. [...] For spirituality to become part of the global solution it will have to become transmodern, moving through modernity, not rejecting the science and technology revolution and the Enlightenment, nor acceding to postmodernity (where all values and perspectives are relativised) or the premodern (where feudal relations are supreme)." (INAYATULLAH, 2009; 6)

Originally attributed by John Elkington (1997), the term Triple Bottom Line is today widely used as the fundamental triadic expression in terms of sustainability general conception.

Commonly associated with the ideal of interdependency with respect to actions and reactions of human activities on the world, the trinomial refers to the reason of equity between the economic, environmental (or ecological) and social spheres linked to ideal of sustainability (People/Planet/Profit).

The Three Spheres of Sustainability

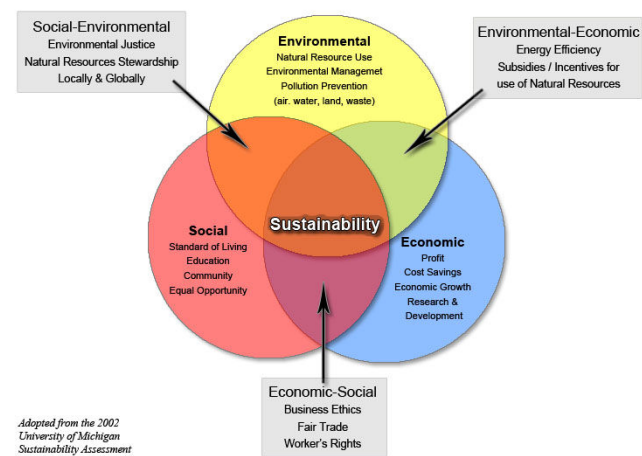


Figure 2. Triple bottom line of sustainability.

Although the Triple Bottom Line (TBL, or 3BL) has practically become the mantra of sustainability at the beginning of the twenty-first century, increasing use of this terminology has exposed gaps that have been shown to be incapable of explaining all human activities, especially with respect to the creation of individual meaning and values (SOOD and TULCHIN, 2016).

Still without consensus as to which principle it should end, many of the world's leading companies and some of the most prominent thinkers have already expressed the need to include a fourth element in the debate of sustainability.

Among a wide range of propositional expressionsmany of them considered only as speculative suggestions guided by particular interests - concepts such as purpose, progress, ethics, and governance, among others, are currently considered to constitute the fourth element, which is hypothetically indispensable to sustainability (i.e. FOURTH BOTTOM LINE, 2016).

According to Social Enterprise Associates (as cited in SOOD and TULCHIN, 2016), the concepts of culture and spirituality are acquiring credibility in this terminological running.

In adopting the concept of culture in consideration of the well-being of the Maori tribe, the general idea of culture, as the fourth bottom line, has been pioneered by the legislation of the government of New Zealand (SCRIMGEOUR and IREMONGER, 2011). According to New Zealand's government approach, sustainable development is, among other things, "a trust that teaches business strategies relating to Maori values to do with Kaitiakitanga (guardianship of the environment), Koha, (ethical investment and giving) and whanaunatanga (maori concepts on social integration)" (Ibid.: 14).

In the context of sustainability, the notions of spirituality or faith are considered in a broader conceptual comprehension when compared to commonly understandings of religion or belief. The idea of spirituality is admitted as something that promotes a meaning to life (EAGLETON, 2007), while focusing on an ideal of transcendence (HICK; 1989).

In this sense, spirituality characterises a primordial need that integrates an individual to a community or a determined culture/nation through their faith and their respective relationship with God (i.e., superior power that can be seen as ethereal and universal). In this integral meaning, the difficulty of qualitative measurement is apparent (INAYATULLAH, 2009; 3).

Far from the speculative conceptions, Stuart Walker argues that: "what is missing from the triple bottom line is explicit recognition that human beings are not only gregarious creatures, but also individuals. Further still, we are individuals who are meaning-seekers" (WALKER, 2011: 127).

With regard to governance, culture and ethics, Walker points out that they are related to social relationships and the development and well-being of communities, which, for the author, "can be included in the social and/or economic considerations" regarding to sustainability (Ibid.).
When arguing that the term spirituality conveys an extensive range of understandings and practices that are intimately related to intrinsic individual meanings, Walker is included in the group of thinkers who adopts this concept as the fourth element of a quadruple bottom line for sustainability (WALKER, 2011: 27-8; 2014: 42, 55-7, 62-5, 70-1, 92-4).

Walker stands out in a particular way, however, when accepting that the term spirituality can be seen as problematic due to the close associations related to the notions of soul, sacred and religion (WALKER, 2011: 127). In more detail, Walker recognises that "for this reason, and recognising the importance of substantive values in linking sustainability with the individual, the fourth element of a quadruple bottom line for sustainability proposed here is 'personal meaning' - a term acknowledging that sustainability has to be relevant and meaningful to the individual person, as well as socially responsible. It is a term that is broad enough to include a wide range of understandings and practices that different people find meaningful and enriching" (Ibid.).

As an etymological abstraction-perhaps lesscontroversial when compared to the word spiritualitythe use of the term personal meaning by Walker points to a "deeper" notion of "inner path/life" (WALKER, 2014: 10-3, 77-9) that is able to embrace matters of conscience and the spiritual or meaning-seeking dimension based on an ethical perspective (Ibid; 57). According to Walker: "It is a path that determines the ethical, cognitive, and pragmatic value of all human action and that transcends sociocultural conventions and differences" (Ibid.).

Figure 3 illustrates the peculiar mode that Stuart Walker prefers to represent his QBL:

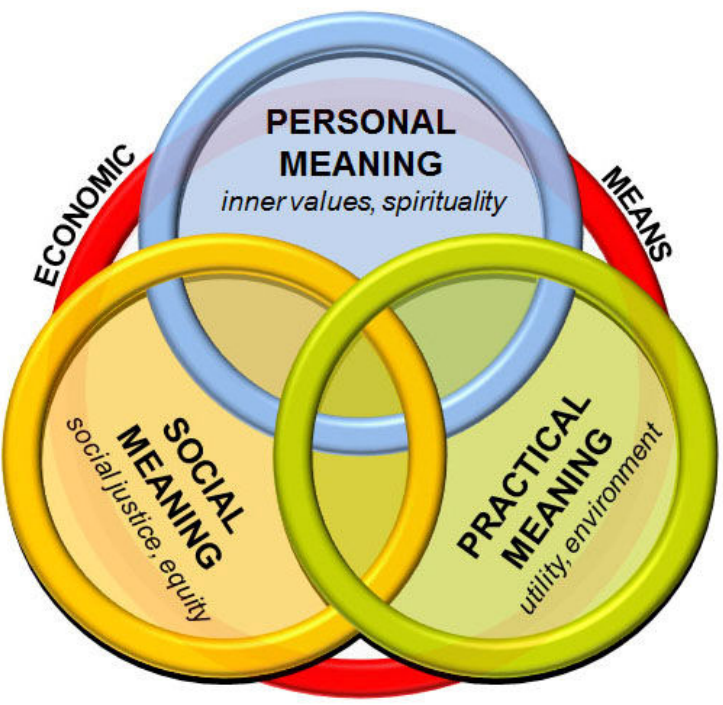

Figure 3. QBL according Stuart Walker.

Assuming that people live in a material world and on a physical planet that per se demands practical utilitarian needs, Walker assumes that we are social creatures who naturally seek for personal meaning and/or purpose (Ibid.: 45). 
According to Walker, these three elements correspond to the three fundamental principles of human existence in the world (Ibid.). The fourth element, economic means, reflects a "human construction rather than a premise and is therefore allocate a secondary role" (Ibid.). For Walker, if what we really want is the sustainable development, then issues of economic significance should "being regarded as a means to an end rather than an end in itself" (Ibid.).

Structured from concentric circles ${ }^{2}$ to re-configure QBL in a simultaneously more embracing and inclusive overview, by subverting the order of elements Walker proposes what he regards of a changed outlook (Ibid.: 92-4). With the intention of expanding perspectives for the areas of concern, Figure 4 represents this particular point of view:

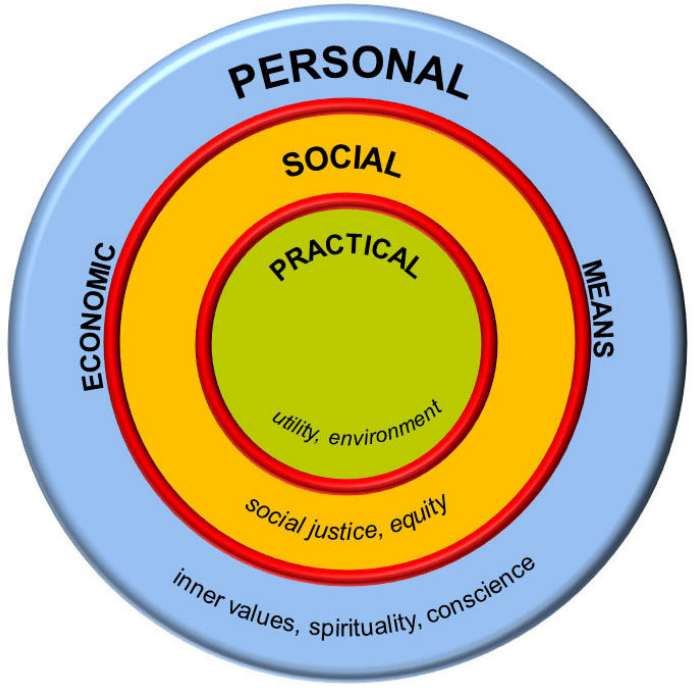

Figure 4. Quadruple bottom line of sustainability: a changed outlook in Stuart Walker.

To formulate the theoretical basis of personal meaning as a forth bottom line, Walker embraces historical (worldviews-SMITH, 2001), psychological (human needs-MASLOW as cited in HUITT, 2007) and philosophical (levels of meaning-HICK, 1989) perspectives (WALKER, 2014: 56-65). According to human needs perspective, for example, Walker leaves the recognised theory (hierarchy) of human motivation proposed by Abraham Maslow (see Figure 5).

\footnotetext{
2 The support of concentric circles as an illustrative diagram to represent Walker's QBL seems to be a direct allusion to the holarchical structure used to express the progressive character of evolution in holistic theories as Koestler (1978), Smuts (1927) Wilber (2001) and so on
}

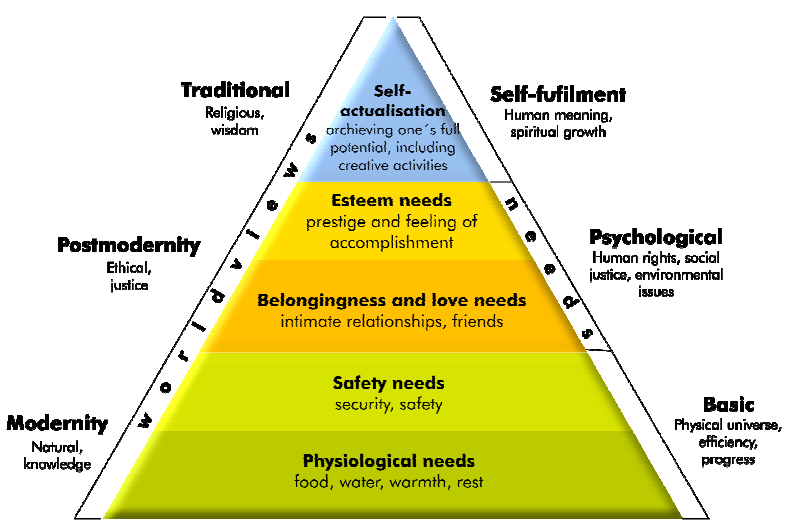

Figure 5. Maslow's hierarchy of needs / Walker's worldviews.

According to Walker, the satisfaction of the two lower stages (of Maslow's pyramid) that are especially related to physiological needs and demands for protection corresponds to the modern emphasis on understanding and controlling the natural environment and utilitarian questions. The two higher stages relate to the needs of love and esteem, which represents the postmodern - or late-modern-emphasis on human rights and social justice concerns. Finally, the highest level of human need, self-actualisation, corresponds to the deepest insights from the traditional (pre-modern) worldview concerning inner development, spiritual growth and ultimate meaning (Ibid: 60 ).

Based on this, Walker (as cited in KRUSSE, 2015: 12) describes the quadruple bottom of lines of design for sustainability in terms of "freedom", as follows:

- Practical Meaning (utility for human benefits and the environmental consequences-few degrees of freedom-we have to furnish our practical needs);

- Social Meaning (a greater degree of freedom-we have the choice to act morally towards others);

- Personal Meaning (maximum degrees of freedomwe can choose to lead an examined like-or ignore this deeper aspect of the human endeavour and fill our time with worldly occupations and distractions);

- Economic Means (a means for achieving the other three-not an end in itself, even though it has become an end in itself in contemporary society).

Precisely regarding the area of design, the studies of Rob Fleming (2013) developed in collaboration with Anne Sherman seem equivalent to the use of the notion of personal meaning (spirituality) as the fourth bottom line, as proposed by Stuart Walker.

From the inclusion of factors such as human experience and consciousness development, Fleming and Sherman describes in detail the QBL as a tool capable of measuring and improving a pedagogy of design for sustainability.

We reproduce the basic definition of Sherman (as cited in FLEMING, 2013: 72), regarding the fourth bottom line in behavioural and experiential terms of the human being: "The Quadruple Bottom Line uses experience as a means to address human behavior, and transform the human-biosphere relationship through physical, emotional, and spiritual consciousness development. At the highest level of this kind of 
relationship, sustainability is an authentic expression of the ways in which humans interact with the world."

\subsection{The notion of a spiritually useful design (Walker)}

"Spiritually useful design can generate artefacts that draw upon tradition, that are more stable and whose appeal is not dependent on originality, newness or technological progress. As such, they represent o radical departure from much of today's consumer-driven product design - a departure that is urgently needed if current, highly damaging and potentially ruinous priorities are to be challenged and redirected. They are also consistent with wisdom teachings and unchanging notions of meaning, unity and deeper human purpose" (WALKER, 2014: 81)

By spiritually useful design, Stuart Walker refers to a creative path of design, whose intention search forms of functional objects associated with wisdom traditions through individual (inner) meanings and values, as virtue and compassion (Ibid.).

According to Walker, "for a century or more, the design's emphasis has been entirely in tune with the ideology of materialism" (Ibid.: 73). In this way, instrumental reason, systematic research of the natural world and data acquisition to advance factual information and empirical knowledge "have been put to human purpose through the continual advancement of science and technology" (Ibid: 73-4). In the words of Walker: "this contemporary understanding of progress, which is physically based, directed towards material benefits and in a constant state of evolution, has had a future-facing trajectory. Consequently, the next 'big thing' has been a major focus for design: it has driven consumption and fuelled economic growth" (Ibid.: 74).

As a reflection of the Newtonian-Cartesian paradigm (CAPRA, 1982; 53-74), which was restricted only to the visible (material/physical) world, this eminently instrumental, functionalist and grounded characteristic of naturalist-materialist understanding was responsible for the promotion of the current worldview about the universe in its process of realisation, analysis and understanding of human phenomena.

Linked to the physical sciences, Walker says that the materialist-naturalist ideology needs to shape the natural, social and cultural environment in order to serve human purposes (Ibid.: 8). However, "physical principles can be, and frequently are, exploited and utilised for human purposes - and these kinds of activities are not valuefree" (Ibid.).

When describing theory and practice of "a less consumptive path" to "beyond the prosaic" design (Ibid.: 76-86), Walker remembers that (ancient) people always create artefacts imbued with a higher or spiritual purpose (Ibid.: 76). In this direction, a possible solution for contemporary design, according to Walker, could be to develop inclusive ideas and forms - trans/supra religious artefacts ${ }^{3}$ - that are supposed to be suited to our spiritually pluralistic times (Ibid.: 80). ${ }^{4}$

In a more holistic and perennial understanding of reality through the appropriation of philosophicalspiritual concepts of millennial religious traditions, the propositional objects presented by Walker incorporate symbolical explorations of temporality, local production, re-signification and re-valorisation of natural aesthetics of (raw) materials in order to evidence such prosaic functionality and allude to notions of deeper human well-being (ethical, aesthetical and moral meanings and values) (PANTALEÃO and PINHEIRO, 2016b).

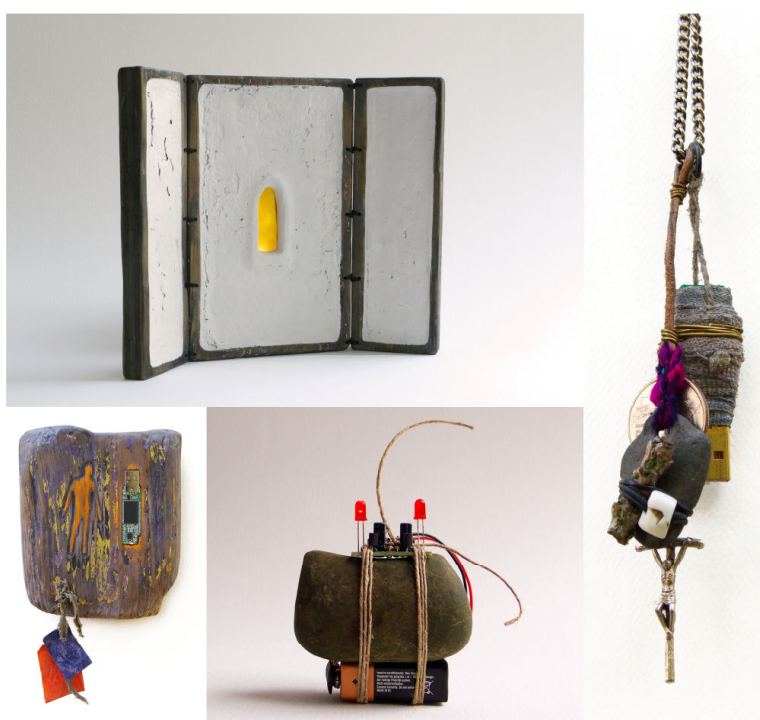

Figure 6. Examples of propositional design by Walker (Source: http://www.stuartwalker.org.uk/)

Summarising his work as "form follows meaning" (WALKER, 2011: 192-205) Walker believes that this is a possible way to transpose the instrumental logic of production efficiency "in which the product too often becomes simply a means to economic growth and shareholder profit" (Ibid.: 4). He seeks to take design beyond the often superficial and harmful features developed over the past decades, which were responsible for establishing consumerism but were little concerned with its own consequences (Ibid.).

As Walker points out: "Form follows meaning-In this way, localised craft is combined with globalised mass-production, natural materials and traditional forms with digital technologies, and short-lived functionality with enduring meaning. Form becomes

\footnotetext{
In accordance with the etymology of the prefix "trans", when adopt the term "trans-religious object" Walker seems to use it to define objects whose symbology presents a kind of versatility capable to permeated "between, across and beyond" of several religions traditions, simultaneously (NICOLESCU, 2010). Regarding the expression "supra-religious objects", Walker seems to refer objects that are "superior" to symbolic appropriation (e.g. metaphorical). These are "supreme objects" located "above" of any symbolical categorization, even of religious nature or any other meaning (ANANDAMURTI, 2013: 359-64)

4 According to Hick's extending proposition of natural meanings (HICK, 1989: 129-71 as cited in WALKER, 2014: 11), today is possible to verified several forms of spirituality. These pluralistic kinds of relating to the spiritual include not only religion but also contemporary non-religious or atheistic forms of spirituality (Ibid.).
} 
delinked from function. [...] Their purpose is as much about aesthetic experience and reflection as about the requisites of functional necessity. The result is a new kind of hybrid object that merges old and new, reason and intuition, global and local, and where form follows meaning” (Ibid.: 192, 204-5).

\section{Conclusions}

Intimately associated with social disparities and largescale environmental destruction, while fostering constantly feelings of dissatisfaction and stimulating consumption and waste, the current understanding of the economic pillar (profit) of sustainability stimulates the incessant material production and marketing of trivial products of short duration, it also promotes practices that are fundamentally at odds with our well-being and happiness.

The more that we recognise the origin of our material culture in relation to the "real world" (Papanek) - or to the "complex world" (CARDOSO, 2012) — with human needs, environment impositions and organisational systems (e.g. politics, economy, etc.), the more we will appreciate the levels of meaning of our own creations.

Beyond People, Profit, Planet, the QBL proposed by Walker is a radical insight into a conciliatory unity between complementary human worldviews (traditional, modern and post-modern or late-modern).

In a favour of an extended understanding of sustainability, the possibility of harmonic connection between science and religion, art and design, theory and practice, and so on corresponds to the two sides of the same whole called people.

We can say, therefore, that intuitive wisdom and intellectual knowledge, empirical data and personal meaning, factual objectivity and experiential subjectivity, as well as the matter and the spirit, complement each other in the same integral eco-logic, which is able to transcend the unsustainable current human activities and move toward "post-materialistic" and "numinous" (MATHEWS, 2013: 27-42) ways of living.

With this paper, we seek to contribute to the reflections of product design, whose approach also integrates a radical dimension of sustainability as an attempt to subvert the current strictly naturalistmaterialist ideology in order to tune into the new systemic, holistic and ecological paradigms of contemporary post-industrial society.

\section{Acknowledgments}

We are grateful to the São Paulo Research Foundation FAPESP and CAPES (grant \# 2014/01356-6) for their financial support of the research that resulted in this article. The authors are responsible for the opinions, assumptions and conclusions or recommendations expressed in this material, which do not necessarily reflect the vision of FAPESP/CAPES.

\section{References}

ANANDAMURTI, S. S. The Supreme Aesthetic Science and Cult of Devotion In. Adorning the Dawn: Discourses on Neohumanist Education. New York: Ananda Marga Publications, 2013.

CAPRA, F. The Turning Point: Science, Society, and the Rising Culture. New York: Bantam Books, 1982.

CARDOSO, R. Design para um mundo complexo. São Paulo: Cosac Naify, 2012

EAGLETON, T. The Meaning of Life. Oxford: Oxford University Press, 2007.

ELKINGTON, J. Cannibals with Forks: The Triple Bottom Line of 21st Century Business. Oxford: Capstone, 1997.

FLEMING, R. Design Education for a Sustainable Future. London: Earthscan, 2013.

FOURTH BOTTOM LINE In. Wikipedia, The Free Encyclopedia, 2016. Available at: https://en.wikipedia.org/wiki/Fourth_Bottom_Line

[Accessed: May 2016].

HICK, J. An Interpretation of Religion: Human Responses to the Transcendent. New Haven, CT: Yale University Press, 1989.

HUITT, W. Maslow's Hierarchy of Needs. Educational Psychology Interactive. Valdosta, GA: Valdosta State University, 2007. Available at:

http://www.edpsycinteractive.org/topics/regsys/maslow. html [Accessed May 2015].

INAYATULLAH, S. Spirituality as the Fourth Bottom Line, 2009. Available at: http://www.metafuture.org/Articles/spirituality_bottom_1 ine.htm [Accessed May 2016].

KOESTLER, A. Janus - A Summing Up. London: Hutchinson \& Co., 1978.

KRUSSE, T. Design Magazine vol. 23. Pontinhas (Odivelas), Portugal, May/June 2015 Available at: https://issuu.com/revistadesignmagazine/docs/designmag azine23 [Accessed: June 2015].

MATHEWS, F. Post-materialism. In. WALKER, S. and GIARD, J. (orgs). The Handbook of Design for Sustainability. London: Bloomsbury Academic, 2013.

NICOLESCU, B. Methodology of Transdisciplinatity Levels of Reality, Logic of the Included Meddle and Complexity. Transdisciplinary Journal of Engineering \& Science 1(1): 19-38, 2010.

PANTAlEÃO, L. F. and PINHEIRO, O. J. Design Sustentável Radical versus Modelo de Melhoria Incremental dos produtos: um olhar panorâmico In: $12^{\circ}$ Congresso Brasileiro de Pesquisa e Desenvolvimento em Design, 2016a, Belo Horizonte. Blucher Design Proceedings v. 9: 2020-33, 2016a. 
Stuart Walker. In: $5^{\circ}$ Simpósio Brasileiro de Design Sustentável, Rio de Janeiro. Anais do $5^{\circ}$ Simpósio Brasileiro de Design Sustentável. São Paulo: Blucher Design Proceedings: 411-22, 2016 b.

PAPANEK, V. Diseñar para el mundo real: ecologia humana y cambio social. Rosario, 17 Madrid-5: Hermann Blume Ediciones, 1977 (original 1971).

The Green Imperative: Natural Design for the Real World. New York: Thames and Hudson, 1995.

SCRIMGEOUR, F. and IREMONGER C. Maori Sustainable Economic Development in New Zealand: Indigenous Practices for the Quadruple Bottom Line, 2011. Available at: https://www.researchgate.net/publication/267971055_M aori Sustainable Economic Development in New Z Zea land_Indigenous_Practices_for_the_Quadruple_Bottom Line [Accessed May 2016].

SMITH, H. Why Religion Matters: The Fate of the Human Spirit in an Age of Disbelief. New York: HarperCollins, 2001.

SMUTS, J. C. Holism and Evolution. London: Macmillan and Co., 1927.

SOOD S. and TULCHIN D. Quadruple Bottom Line Introducing the Concept (online) Available at: http://www.socialenterprise.net/assets/files/TipSheet13Q BL.pdf [Accessed May 2016].

WALKER, S. Designing Sustainability: Making Radical Changes in a Material World, Abingdon: Routledge, 2014.

Extant objects: designing things, as they are. Int. J. Sustainable Design, 1(1): 4-12, 2008.

Sustainable by Design: Explorations in Theory and Practice. London: Earthscan, 2006.

The Spirit of Design: Objects, Environment and Meaning. London: Earthscan, 2011.

WILBER, K. A Brief History of Everything. Boston, MA: Shambhala Publications, 2001. 